\title{
Discussion: Cutter-disc consumption during earth pressure balance tunnelling in mixed strata
}

\section{Khalid Elbaz}

$\mathrm{PhD}$ researcher, State Key Laboratory of Ocean Engineering, School of Naval Architecture, Ocean, and Civil Engineering, Shanghai Jiao Tong University, Shanghai, P. R. China; Collaborative Innovation Center for Advanced Ship and Deep-Sea Exploration (CISSE), Shanghai, P. R. China Shui-Long Shen

Professor, State Key Laboratory of Ocean Engineering, School of Naval Architecture, Ocean, and Civil Engineering, Shanghai Jiao Tong University, Shanghai, P. R. China; Collaborative Innovation Center for Advanced Ship and Deep-Sea Exploration (CISSE), Shanghai, P. R. China

\section{Wen-Chieh Cheng}

Professor, Institute of Tunnel and Underground Structure Engineering, School of Civil Engineering, Xi'an University of Architecture and University, Beilin, Xi'an, P. R. China

\section{Arul Arulrajah}

Professor, Department of Civil and Construction Engineering, Swinburne University of Technology, Victoria, Australia

James Nicholas Shirlaw

Senior Consultant, Golder Associates (Hong Kong) Ltd., Hong Kong

\section{Contribution by J. N. Shirlaw}

The authors present an extremely interesting paper on the driving of an earth pressure balance (EPB) tunnel for Line 9 of the Guangzhou Metro, between Maanshan and Liantang stations (Elbaz et al., 2018). They include many important details, such as tool consumption and a major sinkhole incident.

The sinkhole incident appears to have been responsible for a delay to the tunnelling of about 5 months. Based on the information presented in the paper, this delay was due to various factors including the need to carry out grouting to stabilise the area and permit a long intervention to replace 32 cutting tools, further investigation and grouting for karstic caverns, and slow subsequent advances to re-establish the drive. The total delay, of 5 months, is remarkable in that it constituted over $40 \%$ of the total time required to drive the tunnel.

The authors identify three factors in the causation of the sinkhole: severe wear of the cutting tools, particularly the circumferential discs; the difficulty of maintaining face stability; and the presence of karstic caverns along the alignment. All of these factors were clearly present in the general area where the sinkhole occurred, but it would be useful to establish the causation in greater detail, and understand how it might have been prevented.

The authors give the date, but not the precise location, of the sinkhole. Scaling off Figure 13 of the paper, it appears that the face instability that led to the sinkhole occurred over two to four advances in the area of about ring 630. A major intervention took place at about ring 645 , based on scaling off Figure 11, during which about 32 cutting tools were replaced. At, or just prior to the face instability (R628?), there had been a very dramatic reduction in the advance rate, to about 2 to $5 \mathrm{~mm} / \mathrm{min}$ compared with the typical 40 to $50 \mathrm{~mm} / \mathrm{min}$. The location and advance rates were scaled off Figure 12.
Many of the figures show the level of rockhead. At the approximate location of the sinkhole the rockhead is shown below the invert of the tunnel; if correct, this would mean that the tunnel-boring machine (TBM) was in a full face of soil, having just passed through an area of mixed ground. During the tunnelling in the prior section of mixed ground, the TBM is shown as being driven with a low rate of rotation of the head, about $1 \mathrm{r} / \mathrm{min}$, based on Figure 10, but a high advance rate of typically 30 to $50 \mathrm{~mm} / \mathrm{min}$ (Figure 12). This implies that some of the penetration rates used in the mixed ground were extraordinarily high, up to $50 \mathrm{~mm} /$ revolution. The reviewer would suggest that the use of such high penetration rates in mixed ground could result in

- large impact load on the discs, as they passed from the soil into the rock - higher than would occur at a lower penetration rate

- the risk of damaging the scraper tools through impact with the rock; this would depend on the separation between the discs and the scrapers

- detaching large boulders, slabs or rock ahead of the cutterhead; detached boulders/slabs can be picked up and rolled around with the head, causing loss of ground and tool damage.

As noted above, the face instability appears, based on the figures, to have occurred in a full face of soil. This does not seem to be compatible with the conclusion that the stability problems were related to a karstic cavern. The core boxes from the borehole shown in Figure 14(b) are poorly labelled, but appear to be from well below the level of the tunnel invert. Is it possible that what was encountered at the location of the face instability was a slump zone, rather than a karstic cavern?

In order to understand more about the face instability that caused the sinkhole it would be useful if the authors could provide the following information 
(a) the number of each of the types of cutting tool (scrapers, bucket lips and discs) replaced at the intervention at about R645; the number of each type of tool replaced overall is given in the paper, but the numbers for the intervention just after the location of the sinkhole are not given

(b) for the discs that were replaced at about R645, what number were replaced due to general wear/abrasion, and what number showed evidence of impact damage - in other words, were broken or chipped

(c) the distance by which the tips of the discs were in advance of the tips of the scrapers

(d) the precise location of the sinkhole, in terms of the ring to be built when the face was under the centre of the sinkhole

(e) the precise location of the intervention carried out after the sinkhole occurred

( $f$ ) graph(s) showing the range of face pressure and the penetration rate $(\mathrm{mm} /$ revolution) plotted just over R600 to R650, with the locations of the sinkhole and subsequent intervention also shown.

It would also be appreciated if the authors could comment further on the ground conditions in the area under the sinkhole, at tunnel level. Was the TBM in a full face of soil, or was it in a mixed face of rock and soil, and, if the latter, what was the proportion of rock to soil in the face? There should be extensive evidence for this from the tunnelling, drilling and grouting in the area. If the face consisted of mixed ground and there was extensive damage to the disc cutters, then there would have been problems in excavating the rock; at the same time soil could have been drawn into the TBM, leading to over-excavation. This explanation would not apply in soil; if the face comprised only soil at this point, then an alternative explanation, such as inadequate face pressure or breaking the arch over a slump zone, would have to be sought.

A question arising out of this case history would be: how could the tunnelling practice have been improved, thus avoiding the development of the sinkhole, and the consequent major delay? One option would have been to use a variabledensity TBM instead of an EPB TBM. However, only a relatively small proportion of the tunnelling was in limestone rock or mixed ground, and the increased cost and complexity of tunneling with a variable-density TBM might make this solution less than optimal in the specific ground conditions at the site. Improving the EPB tunnelling practice might involve

increased ground investigation using both geophysical methods and drilling, to identify caverns and slump zones, followed by targeted grouting

- reducing the penetration rate in mixed ground

- increasing the frequency of interventions in mixed ground, to inspect and, where necessary, replace cutting tools.
Related to the last bullet point, in Singapore some tunnelling specifications have required, as a minimum, at least one intervention per $50 \mathrm{~m}$ of tunnelling in mixed ground; this is to reduce the risk that failure of a single disc can lead to cascading failure of further discs and then damage to disc housings. Shirlaw (2016) cites an example of a slurry TBM drive in Hong Kong where, on average, there was one intervention per $7 \cdot 1 \mathrm{~m}$ length of tunnel driven in mixed ground of saprolite and granite. The Hong Kong granite is stronger and much more abrasive than the limestone discussed in the paper, so is not directly comparable to the case history presented by the authors. Nevertheless, the number of damaged tools that had to be replaced at about R645 does suggest that it would have been wise to increase the frequency of interventions in the mixed ground, compared with the actual frequency.

It would be appreciated if the authors could comment further on the causation of the sinkhole and what measures, in retrospect, might have avoided the development of the sinkhole.

\section{Authors' reply}

The authors appreciate the detailed valuable comments for this discussion on their paper. The discussion is very helpful to the authors, in order to improve knowledge of the technical work and the organisation of the paper. The authors would like to express their sincere apology to readers, as they have just realised that Figures 13 and 14(a) contained some inaccurate content. The location of the collapsed sinkhole was found not to be within zone 6 , but in fact was located at ring 44 in zone 1 , as indicated by the corresponding author's previously published work (Cui et al., 2015). The triggering mechanism of this collapsed sinkhole can mainly be attributed to the instability of the excavation face. The sinkhole occurred in December 2013 rather than at the end of April 2014. During the initial construction phase, some rectifications were made to optimise the tunnelling process. The applied pressure of foam was set at an inappropriate value, much higher than the overburden pressure. Foam spilled out from the ground surface, triggering the formation of this sinkhole. The authors would like to provide a corrigendum to delete Figure 14 in the original paper and modify Figure 13, as shown in this discussion.

In fact, the sinkhole was not found to be responsible for the construction delay of about 5 months. This delay was linked to the replacement of cutter tools, machine maintenance and additional geological investigations. Although there were other influencing factors involved in this zone, the authors overlooked these influencing factors because they were outside the scope of this study.

To prevent similar incidents, more detailed investigations for this tunnelling project were conducted, with more boreholes installed. Additionally, the advancement rate was reduced to re-establish the drive. 


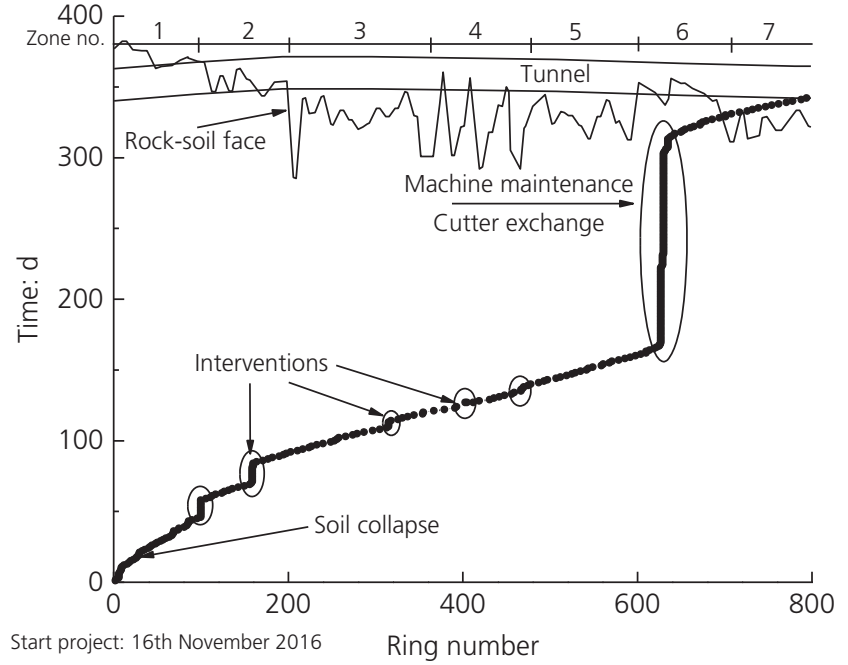

Figure 13. Relationship between the time consumed and the tunnelling distance for Ma-Lian section

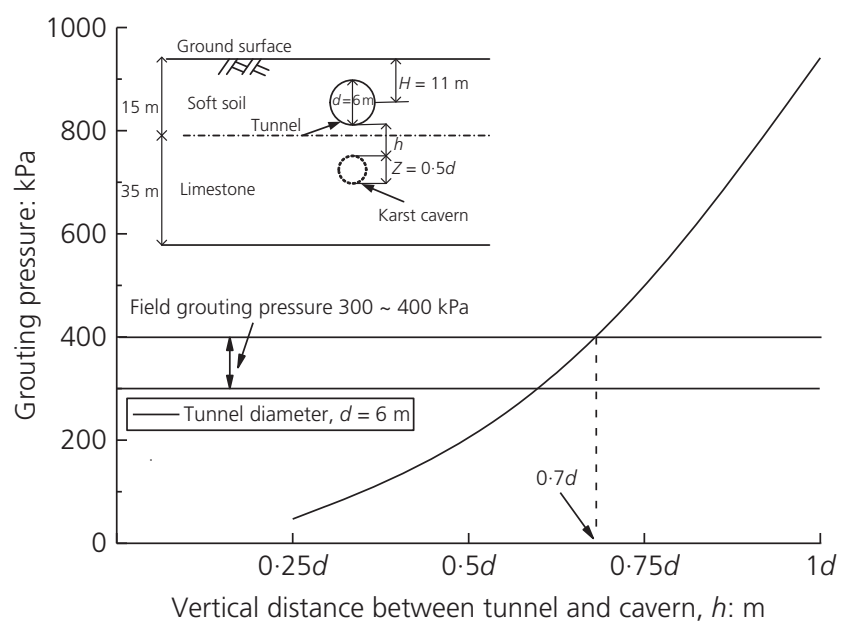

Figure 15. Safe distance between tunnel and karst cavern
For further verification, the authors conducted a numerical simulation, Abaqus 3D model, based on the previous geological section and concluded that the vertical safe distance between tunnel and karst cavern could be described as follows.

When the roof of an untreated cavern is damaged by an external force, soil instantly enters the cavern developed in the limestone. Thus, it will directly or indirectly affect the safety of the shield tunnel. The vertical distance from the cavern boundary to the tunnel border determines the degree of influence of the karst collapse on the tunnel structure. To check the safety, finite-element analysis was conducted and the results are shown in Figure 15 (Cui, 2016). Figure 15 shows the relation between the critical grouting pressure and the vertical distance between the tunnel and cavern. During the field construction of the Ma-Lian section, the grouting pressure of the shield tail varied between 100 and $400 \mathrm{kPa}$. It can be deduced that the critical vertical distance between tunnel and cavern occurred at $0 \cdot 7 d$, meaning that the cavern at $0 \cdot 7 d$ below the tunnel floor needs to be treated, otherwise it will cause a crucial instability issue in the tunnel.

\section{REFERENCES}

Cui QL (2016) Construction Mechanism and Control Technology for Shield Tunneling near the Interface between Karst Caves and by Sandy Strata. PhD dissertation, Shanghai Jiao Tong University, Shanghai, China.

Cui QL, Wu HN, Shen SL, Xu YS and Ye GL (2015) Chinese karst geology and measures to prevent geohazards during shield tunnelling in karst region with caves. Natural Hazards 77(1) $129-152$.

Elbaz K, Shen SL, Cheng WC and Arulrajah A (2018) Cutter-disc consumption during earth pressure balance tunnelling in mixed strata. Proceedings of the Institution of Civil Engineers - Geotechnical Engineering 171(4): 363-376, https://doi.org/10.1680/jgeen.17.00117.

Shirlaw JN (2016) Pressurised TBM tunnelling in mixed face conditions resulting from tropical weathering of igneous rock. Tunnelling and Underground Space Technology 57: 225-240. 